\title{
Effect of Cola Nitida on Immediate Post Moderate-Exercise Cardiopulmonary Response in Young Adult Male
}

\author{
*OMOROGIUWA, A; EIYA, BO
}

\author{
Department of Physiology, School of Basic Medical Sciences, College of Medical Sciences University of Benin, Benin City, Nigeria \\ *Corresponding Author Email: ask4ade2006@yahoo.com; arthur.omorogiuwa@uniben.edu \\ Tel: +2347039460340
}

\begin{abstract}
The study aimed at evaluating post-exercise cardiopulmonary responses in young adult males who masticated and ingested Cola nitida prior to moderate exercise. The cardiopulmonary responses studied were heart rate, pulse pressure and respiratory rate. A total of 20 apparently healthy male volunteers were studied. They were subdivided into 4 subgroups A, B, C and D. The subjects in Group A served as control and were not given Cola nitida, while the subjects in groups B, C and D were given $100 \mathrm{mg} / \mathrm{kg}, 200 \mathrm{mg} / \mathrm{kg}$ and $400 \mathrm{mg} / \mathrm{kg}$ of Cola nitida respectively. Prior to the exercise baseline cardiopulmonary parameter were recorded using standard clinical methods. The subjects subsequently chewed and ingested appropriate doses of Cola nitida. Ninety minutes post ingestion; they warmed up for 5 minutes and then mounted the threadmill at an inclination of $2 \%$ at $5 \mathrm{mph}$ for 30 minutes. Thereafter the immediate cardiopulmonary responses such as pulse rate, pulse pressure and respiratory rate were recorded one minute post exercise. Results were presented as Mean \pm SD and analyzed using appropriate ANOVA with post hoc Tukey HSD test and $\mathrm{p}<0.05$ was considered statistically significant. Overall, Cola nitida potentiated $(\mathrm{p}<0.05)$ the percentage increase in cardiopulmonary responses observed in this study. However, irrespective of the dose of Cola nitida ingested the percentage increase in pulse rates were not different $(\mathrm{p}>0.05)$ amongst test groups. Cola nitida increases the post-moderate-exercise pulse rate, pulse pressure and respiratory rate in young male adults.
\end{abstract}

\section{DOI: https://dx.doi.org/10.4314/jasem.v22i12.3}

Copyright: Copyright $\odot 2018$ Omorogiuwa and Eiya. This is an open access article distributed under the Creative Commons Attribution License (CCL), which permits unrestricted use, distribution, and reproduction in any medium, provided the original work is properly cited.

Dates: Received: 21 November 2018; Revised: 28 November 2018; Accepted 12 December 2018

Keywords: exercise, cola nitida, cardiopulmonary, young male

Exercise is an organized and coordinated musculoskeletal movement that aims at keeping the body in a state of physical and mental wellbeing. Exercise has also been viewed as any bodily activity that enhances or maintains physical fitness and overall health and wellness (Kylasov and Gavrov, 2011). However, the muscular activity during exercise generates strength and interrupts homeostasis (Araujo, 2001). Exercise can also be defined exercise as an activity of systematic repetitions of oriented movements feature with consequent increase on oxygen intake due to muscular demand thus generating work (Barrose-Neto et al., 1999). Exercise increases the density of capillaries due to angiogenesis (Kwak et al., 2018; Ding et al., 2006) with an overall improvement of muscular blood flow and oxygenation. The regular practice of physical exercises promotes important autonomic and hemodynamic adaptations that will influence the cardiovascular system (Rondon and Brum, 2003) with the objective of maintaining the cellular homeostasis in face of the increment of the metabolic demands. Overall the increased metabolism and oxygen demand is associated with some immediate cardiopulmonary responses such as increased heart rate and respiratory rate.

The physiological effects of the physical exercise may be classified into immediate acute, late acute and chronic. The acute effects, also called responses, are those that occur in direct association with the exercise session; the immediate acute effects are those that occur in the peri and post-immediate physical exercise periods, with elevation on the cardiac frequency, pulmonary ventilation and sidoresis, while the late acute effects occur along the first 24 or 48 hours (many times up to 72 hours) after a physical exercise session, being identified in the slight reduction on the tensional levels, especially in hypertensive individuals, in the expansion of the plasmatic volume, in the improvement of the endothelial function (Araujo, 2001) and in the action improvement and increase on the insulin sensitivity in the skeletal musculature (Rondon and Brum, 2003). Finally, the chronic effects, also called as adaptations resulting from the frequent and regular exposure to physical exercise sessions and represent morphofunctional aspects that distinguish an individual physically trained from an untrained

*Corresponding Author Email: ask4ade2006@yahoo.com; arthur.omorogiuwa@uniben.edu

Tel: +2347039460340 
individual, presenting as typical examples the rest relative bradycardia, the muscular hypertrophy, the physiological left ventricular hypertrophy and the increase on the maximal oxygen intake $\left(\mathrm{VO}_{2}\right.$ maximum) (Araujo, 2001). .

The genus Cola,Kolanut is the seed of a tree that belongs to the steruculiacee family. The nutrient composition of kola nut includes $8.90 \%$ protein, $0.92 \%$ fat and $2.40 \%$ ash (Jayeola, 2001). The two main constituents of kola are caffeine and theobromine; but its pharmacological/toxicological and psychoactive effects are traceable to the caffeine content (Burdrock et al., 2009; Kaplan and Sadock, 2003). Just like exercise kola nut has powerful stimulants that counteract fatigue and enhance intellectual activity. It also suppresses thirst and hunger which may be desirable during exercise. Thus ingesting kola nut before exercise may have more efficient cardiovascular responses to meet up with the metabolic and oxygen demand. This study is therefore aimed at determining the effect of exercise on pulse pressure, respiratory rate and pulse rate in young adult male that has ingested Cola nitida.

\section{MATERIALS AND METHOD}

Study Design: This was a cross sectional study of 20 apparently healthy male volunteer students of the University of Benin. Informed consent was obtained from every volunteer for the study. The twenty subjects were further divided into 4 subgroups A, B, C and D with five subjects in each group. Questionnaires were administered to subjects to extract Bio data from them. The inclusion Criteria for the study were age between 20-24 years, height between 155-165m and weight between $48-60 \mathrm{~kg}$. The exclusion criteria for the study were anemia, peptic ulcer disease, history cardiac disease, asthma, HbSS, history of smoking and history of alcohol use

Measurement of Cardiopulmonary parameters, administration of Cola nitida and Exercise protocol: Baseline cardiopulmonary parameters namely, pulse rate, pulse pressure and respiratory rate were measured using standard clinical methods. Subsequently Cola nitida was administered as follows: Group A $(\mathrm{n}=5)$; Fasting (nil Cola nitida); Group B $(\mathrm{n}=5)$; had $100 \mathrm{mg} / \mathrm{kg}$ of Cola nitida ingested orally per body weight; Group C $(\mathrm{n}=5)$; had $200 \mathrm{mg} / \mathrm{kg}$ of Cola nitida ingested orally per body weight; Group D $(n=5)$; had $400 \mathrm{mg} / \mathrm{kg}$ of Cola nitida ingested orally per body weight.

Ninety minutes post fasting and ingestion of the Cola nitidida, subjects were asked to warm up for 5 minutes and subsequently mounted the thread mill at an inclination of $2 \%$ and a speed of $5 \mathrm{mph}$ for 30 minutes. Thereafter respiratory rate, Pulse rate and blood pressures were recorded in the first one minute of exercise and that reflected the immediate post exercise cardiopulmonary response.

Calculation of Pulse pressure ( $\mathrm{mmHg}$ ): The pulse pressure $(\mathrm{Pp})$ was calculated from the difference of the measured systolic and diastolic pressures as expressed mathematically as;

$$
P_{p}=P_{s}-P_{d}
$$

Where Ps $=$ systolic pressure and $\mathrm{Pd}=$ diastolic pressure

The percentage change in immediate cardiopulmonary response (\% CPR) was estimated as

$$
\% \mathrm{CPR}=\frac{\mathrm{CPV}_{\text {Post }}-\mathrm{CPV}_{\text {Pre }}}{\mathrm{CPV}_{\text {Post }}}
$$

Where $\mathrm{CPV}_{\text {Post }}$ Post-exercise cardiopulmonary value and $\mathrm{CPV}_{\mathrm{Pre}}=$ Pre-exercise cardiopulmonary value

Where cardiopulmonary values can be pulse rate, pulse pressure and pespiratory rate.

Statistical Analysis: Results were presented as percentage increase as mean \pm SEM in Bar chart using Excel 2010. Statistical analysis was done using one way ANOVA with Post-Hoc Tukey Honest Significant Difference test

\section{RESULTS AND DISCUSSION}

All subjected that participated in the study completed the study and they were aged between 18 and 22 years with body mass index falling within normal range for all groups. The immediate post-exercise percentage increase in pulse pressure, heart rate and respiratory rate are represented in figures 1-3. The immediate pulse pressure response in the control subjects was that of an increase. This indicates that exercise increases the contractility potential of the heart muscle to meet up with metabolic demand associated with it. Studies have shown that during exercise, there is a desirable increase in mean arterial arterial blood pressure due to resetting of the arterial baroreflex. This resetting helps to avert severe arterial hypotension during intense activity. Contractility of the myocardium is also enhanced by the sympathetic nervous system, which is activated during physical activity. Thus, an increase in the left ventricular end-diastolic volume and a decrease in the left ventricular end-systolic volume (LVESV) account for the increase in stroke volume 
during light to moderate dynamic exercise (Poliner et al., 1980). Furthermore, the increased pulse pressure was further enhanced in subjects who took varying doses of Cola nitida.with the greatest increase recorded in the subjects who ingested $400 \mathrm{mg} / \mathrm{kg}$. Thus there was a direct relationship between the the increased pulse pressure response and the dose of Cola nitida ingested. During exercise the increase in mean arterial pressure is a normal and desirable response which is traceable to the resetting of the arterial baroreflex to a higher pressure. Without such resetting, the body would experience severe arterial hypotension during intense activity (Rowell, 1986).

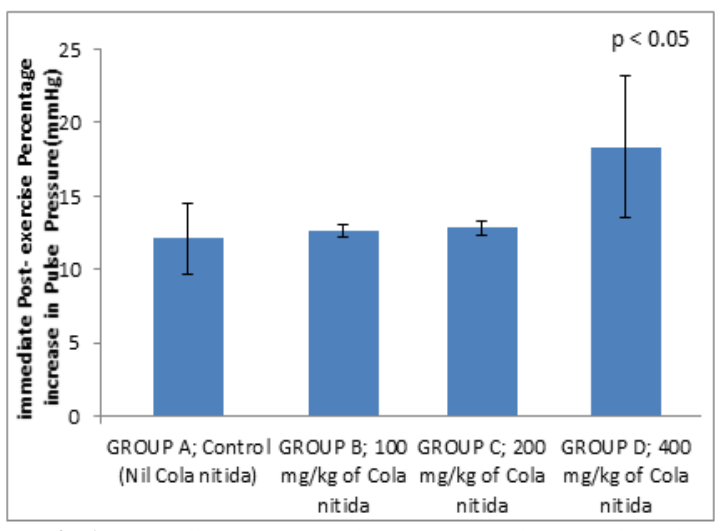

Fig 1: Immediate post exercise percentage increase in pulse pressure in mean $\pm \mathrm{SD}, \mathrm{p}<0.05$ is considered statistically significant

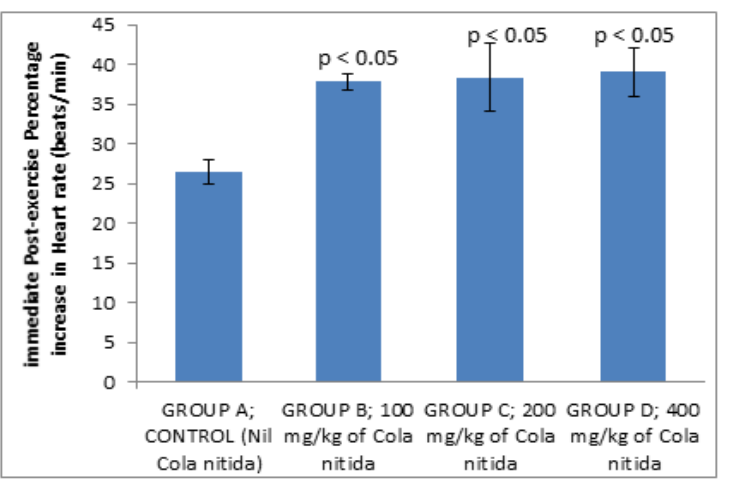

Fig 2: Immediate post exercise percentage increase in Heart rate in mean $\pm \mathrm{SD}, \mathrm{p}<0.05$ is considered statistically significant

Heart rate increases immediately at the onset of activity as a result of parasympathetic withdrawal. As exercise continues, further increases in heart rate are due to the action of the sympathetic nervous system ${ }^{11}$. In this study, the percentage increase in heart rate was lower in the control subjects who did not ingest Cola nitida compared to the groups of subjects who ingested the various doses of Cola nitida. However, in the groups of subjects who ingested various doses of cola nitida, there was no significant difference in the percentage increase in the immediate heart rate measurement. Hence the function of Cola nitida in potentiating increased heart rate induced by exercise was not affected by the various doses used in this study. The relative increase in heart rate observed in the groups who masticated and ingested Cola nitida gives credence to the study implicating methlxanthines (a component of Cola nitida) as a stimulant of heart muscle contraction (Tazzeo et al., 2012).

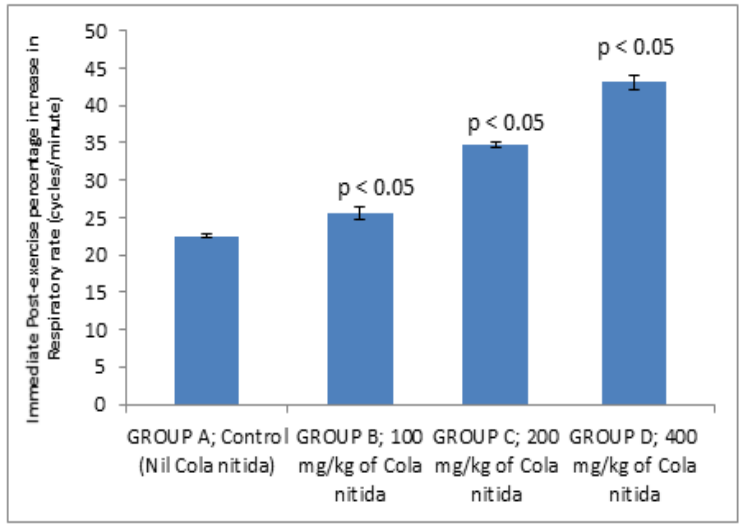

Fig 3: Immediate post exercise percentage increase in respiratory rate in Mean $\pm \mathrm{SD}, \mathrm{p}<0.05$ is considered statistically significant

Moderate intensity aerobic training improves respiratory function (Chaitra and Puranik, 2012; Cheng et al., 2003). In this study, moderate exercise increased the respiratory rate by $22.4 \%$ and there was a step wise further increase in the respiratory rate following increasing doses of Cola nitida. Cola nitida thus has a potentiating effect on exercise induced hyperventilation. Kola nuts contain large amounts of caffeine and theobromine and are used as a stimulant (Jayeola, 2001). Theophylline relaxes bronchial muscles and has been used in the treatment of asthma. Caffeine is bronchodilator that increases minute ventilation in patients with chronic obstructive lung disease and has been utilized as a respiratory stimulant in neonates with recurrent apneic episodes (Murat et al., 1981; Gong et al., 1986).

Conclusion: This study suggests that Cola nitida increases post-moderate-exercise pulse rate, pulse pressure and respiratory rate in young male adults. Furthermore, the increases in pulse pressure were observed to be the same across all doses used in this study.

\section{REFERENCES}

Araújo, CGS (2001). Physiology of physical exercise and high blood pressure. Hypertension. 6 (10):47 
Barros-Neto, TL; César, MC; Tebexreni, AS (1999). Exercise physiology. Preparaçãofisiológica, avaliaçãomédica, aspectosespeciais e preventivos. $5(2): 3-13$

Burdrock, GA; Carabian, IG; Crincoli, CM (2009). Safety Assessment of kola nut extract as a food ingredient. Food. Chem. Technol. 47(8):17251732.

Chaitra, N; Puranik, M (2012). Moderate intensity aerobics training improves pulmonary function in young Indian men. Biomed Res. 23(2):231-300

Cheng, YJ; Macera, CA; Addy, CL et al. (2003). Effects of physical activity on exercise tests and respiratory function. .J. Sports Med. 37(4):521529

Ding, YH1; Li, J; Zhou, Y; Rafols, JA; Clark, JC; Ding, Y (2006).Cerebral angiogenesis and expression of angiogenic factors in aging rats after exercise. Curr. Neurovasc. Res. 3(1):15-23.

Gong, H; Simmons, MS; Tashkin, DP; Hui, KK; Lee, EY (1986). Bronchiodialator effects of caffeine in coffee. Chest. 89:335-342

Jayeola, CO (2001). Preliminary studies on the use of kolanuts (Cola nitida) for soft drink production. J. Food Technol. Afr. 6(1): 25-26

Kaplan, HL; Sadock BJ (2003). Synopsis of psychiatry; Behavioural Sciences/clinical psychiatry; Behavioural sciences/clinical psychiatry, 9th Edition.
Kwak, SE; Lee, JH; Didi, Z; Song, W (2018). Angiogenesis: focusing on the effects of exercise in aging and cancer. $\mathbf{J}$ Exerc Nutrition Biochem. 22(3): 21-26.

Kylasov, A and Gavrov, S (2011). Diversity Of Sport: non-destructive evaluation. Paris: UNESCO: Encyclopedia of Life Support Systems. pp. 46291. ISBN 978-5893172270.

Murat, I; Moriette, G; Blin, MC (1981). The efficacy of caffeine in the treatment of recurrent idiopathic apnea in premature infants. J. Pediatr. 99:984-989

Poliner, LR; Dehmer, GJ; Lewis, S; Parkey, RW; Blomqvist, CG; Willerson JT (1980). Left ventricular performance in normal subjects: A comparison of the responses to exercise in the upright supine positions. Circulation. 62(2):528534

Rondon, MB; Brum PC (2003). Effect of exercise on hypertension. Review on hypertension. 10:134147

Rowell, LB (1986). Human circulation regulation during physical stress. New York: Oxford University Press.

Tazzeo, T; Bates, G; Roman, NH; Laucon, A; Khasnis, DM; Eto, M; Janssen, JL (2012). Caffeine relaxes smooth muscle through actin depolymerization. Am J Physiol Lung Cell Mol Physiol. 303 (4): 334-342 